\title{
Validity of physician-diagnosed COPD in relation to spirometric definitions of COPD in a general population aged 50-64 years - the SCAPIS pilot study
}

\author{
This article was published in the following Dove Press journal: \\ International journal of COPD \\ 4 August 2017 \\ Number of times this article has been viewed
}

\section{Kjell Torén ${ }^{1,2}$ \\ Nicola Murgia ${ }^{1,2}$ \\ Anna-Carin Olin' \\ Jan Hedner ${ }^{3}$ \\ John Brandberg ${ }^{4}$ \\ Annika Rosengren ${ }^{5}$ \\ Göran Bergström ${ }^{5}$}

'Section of Occupational and

Environmental Medicine, Sahlgrenska Academy, University of Gothenburg, Gothenburg, Sweden; ${ }^{2}$ Section of Occupational Medicine, Respiratory Diseases and Toxicology, University of Perugia, Perugia, Italy; ${ }^{3}$ Department of Medicine/Lung Medicine, Sahlgrenska Academy, University of Gothenburg, Gothenburg, ${ }^{4}$ Department of Radiology, Institute of Clinical Sciences, Sahlgrenska Academy, University of Gothenburg, Gothenburg, ${ }^{5}$ Department of Molecular and Clinical Medicine, Institute of Medicine, Sahlgrenska Academy, University of Gothenburg, Gothenburg, Sweden
Correspondence: Kjell Torén Section of Occupational and Environmental Medicine, Institute of Medicine, University of Gothenburg, Box 4I4, S-405 30 Gothenburg, Sweden $\mathrm{Tel}+46702190711$

Email kjell.toren@amm.gu.se
Background: In epidemiological studies, items about physician-diagnosed COPD are often used. There is a lack of validation and standardization of these items.

Materials and methods: In a general population-based study, 1,050 subjects completed a questionnaire and performed spirometry, including forced expiratory volume in 1 second $\left(\mathrm{FEV}_{1}\right)$ and forced vital capacity (FVC) after inhalation of $400 \mu \mathrm{g}$ of salbutamol. COPD was defined as the ratio of $\mathrm{FEV}_{1} / \mathrm{FVC}<0.7$ after bronchodilation. Physician-diagnosed COPD was defined as an affirmative answer to the single item: "Have you ever had COPD diagnosed by a physician?", physician-diagnosed COPD/emphysema as an affirmative answer to any of the two single items; "Have you ever had COPD diagnosed by a physician?" or "Have you ever been told by a physician that you have emphysema?", physician-diagnosed chronic bronchitis as an affirmative answer to; "Have you ever been told by a physician that you have chronic bronchitis?" and physician-diagnosed COPD, emphysema or chronic bronchitis was defined as an affirmative answer to either of the three items above.

Results: For the single item about physician-diagnosed COPD, the sensitivity was around 0.11 and the specificity was almost 0.99 in relation to COPD. The sensitivity of the combined items about COPD/emphysema in detecting COPD was 0.11 and the specificity was high, 0.985 . When the items about physician-diagnosed COPD, emphysema or chronic bronchitis were merged as one entity, the sensitivity went up (0.13) and the specificity went down (0.95).

Conclusion: Items about physician-diagnosed COPD have low sensitivity but a very high specificity, indicating that these items will minimize the proportion of false positives. The low sensitivity will underestimate the total burden of COPD in the general population. Items about physician-diagnosed COPD may be used in studies of risk factors for COPD, but are not recommended in prevalence studies.

Keywords: validity, questionnaire, general-population, obstructive lung diseases, epidemiology

\section{Introduction}

COPD is an important cause of morbidity and mortality, and it has been estimated that COPD is the third leading cause of death worldwide. ${ }^{1}$ Exposure to tobacco smoke is the most important cause of COPD with population attributable fractions around $70 \%-80 \%{ }^{1}$ Other important potential risk factors are occupational exposure to vapor, gas and dust and fumes and exposure to indoor air pollutants including passive smoking. ${ }^{2-4}$

Spirometry after bronchodilatation is crucial for the diagnosis of COPD defined as the fixed ratio of forced expiratory volume in 1 second $\left(\mathrm{FEV}_{1}\right) /$ forced vital capacity 
(FVC) $<0.7 . .^{5}$ However, the GOLD recommendations of the use of the fixed ratio of $\mathrm{FEV}_{1} / \mathrm{FVC}<0.7$ have been challenged because a definition based on an $\mathrm{FEV}_{1} / \mathrm{FVC}<0.7$ may cause overestimation of COPD in the older population in epidemiological studies. ${ }^{6}$ An alternative approach is to use the lower limit of normal (LLN) of $\mathrm{FEV}_{1} / \mathrm{FVC}<0.7$ as a cutoff. ${ }^{7}$ The LLN is calculated using the distribution in a reference material adjusted for age, sex and height. Spirometric diagnosis of COPD, irrespectively if the GOLD approach or the LLN approach is applied, is sensitive, meaning that a high proportion of the diagnosed subjects has mild disease or are asymptomatic, which may result in a substantial proportion of false-positive diagnoses. ${ }^{6,7}$

In epidemiological studies investigating the risk of disease in relation to certain risk factors, there is preferential to have operational disease definitions with (very) high specificity. ${ }^{8}$ Disease definitions with high specificity imply lower sensitivity, which altogether means that the fraction of false negatives increases and the fraction of false positives decreases. Outcome definitions using questionnaire items about self-reported physician diagnosed disease, such as asthma or diabetes, has been shown to have a high specificity. ${ }^{9-11}$

Items about physician-diagnosed COPD are used in epidemiological studies, but there is an obvious lack of studies validating items about physician-diagnosed COPD in relation to a spirometric gold standard. In a previous study performed in another population, we have validated the item "Have you been diagnosed by a physician as having COPD or emphysema?" against the ratio of $\mathrm{FEV}_{1} /$ FVC $<0.7 .^{12}$ The specificity was very high, 0.997 , and the sensitivity was low, 0.057 . However, the validation was in relation to spirometry before bronchodilation. To the best of our knowledge, we have not found any validation studies in general population settings validating questionnaire-based physician-diagnosed COPD in relation to spirometric diagnosis of COPD. We have now performed a validation study in the general population where we have access to spirometry before and after bronchodilation. We will have the possible to validate these items in relation to different definitions of airways obstruction and COPD.

\section{Materials and methods}

The study data were derived from the pilot part of the Swedish CArdioPulmonary bioImage Study (SCAPIS Pilot), a Swedish general population-based study. ${ }^{13-15}$ Briefly, a randomly selected population sample including 2,243 adults aged 50-64 years were invited to the investigation and
1,111 subjects agreed to participate. All of these subjects answered an extensive respiratory questionnaire comprising items about physician-diagnosed COPD, emphysema, asthma and chronic bronchitis, respiratory symptoms and smoking habits.

Dynamic spirometry, including $\mathrm{FEV}_{1}$ and FVC, was performed. All spirometric maneuvers were performed before and 15 minutes after inhalation of $400 \mu \mathrm{g}$ of salbutamol using a nose clamp with the subject in the sitting position. A Jaeger Master Screen PFT (Hoechberg, Germany) was used for all measurements. Predicted values of $\mathrm{FEV}_{1}, \mathrm{FVC}$ and $\mathrm{FEV}_{1} /$ FVC were calculated based on a recent Swedish population and $\mathrm{FEV}_{1}$ and $\mathrm{FVC}$ are expressed as percent predicted. ${ }^{16,17}$

\section{Definitions}

Airways obstruction was defined as the ratio of $\mathrm{FEV}_{1}$ / $\mathrm{FVC}<0.7$ before bronchodilation. $\mathrm{COPD}_{\mathrm{GOLD}}$ was defined as the ratio of $\mathrm{FEV}_{1} / \mathrm{FVC}<0.7$ after bronchodilation. ${ }^{5} \mathrm{COPD}_{\mathrm{LLN}}$ was defined as the ratio of $\mathrm{FEV}_{1} / \mathrm{FVC}$ below the $\mathrm{LLN}$ after bronchodilation. $^{7}$

Physician-diagnosed COPD was defined as an affirmative answer to the single item: "Have you ever had COPD diagnosed by a physician?"

Physician-diagnosed COPD/emphysema was defined as an affirmative answer to any of the two single items: "Have you ever had COPD diagnosed by a physician?" or "Have you ever been told by a physician that you have emphysema?"

Physician-diagnosed chronic bronchitis was defined as an affirmative answer to: "Have you ever been told by a physician that you have chronic bronchitis?"

Physician-diagnosed COPD, emphysema or chronic bronchitis was defined as an affirmative answer to either of the three items above.

Physician-diagnosed asthma was defined as an affirmative answer to "Have you ever had asthma diagnosed by a physician?"

Smoking was categorized as current smokers, former smokers or never-smokers. Former smokers were defined as those who have smoked for at least 1 year but not during the last year. In this analysis, current smokers and former smokers were categorized as ever-smokers. The study was approved by the Regional Committee of Ethics in Umeå, 2010/228-31, and all included subjects gave their written informed consent to participate in the study.

\section{Statistics}

All calculations were performed using SAS version 9.2 (SAS Institute, Cary, NC, USA). The 95\% CIs for specificity, 
sensitivity, positive predictive value (PPV) and negative predictive value (NPV) were calculated using exact methods. 95\% CIs were also calculated applying exact methods.

\section{Results}

Of the 1,111 subjects, 61 were excluded because of incomplete data resulting in a final study population of 1,050 subjects. Descriptive data on age, sex, smoking, lung function and prevalence of airways obstruction and COPD according to different definitions are shown in Table 1.

Twenty-one subjects $(2.0 \%)$ responded affirmatively to the single item about physician-diagnosed COPD, seven subjects $(0.7 \%)$ responded affirmatively to the item about physician-diagnosed emphysema and three subjects affirmed both items. Hence, 25 subjects (2.4\%) were defined as having physician-diagnosed COPD/emphysema, that is, responding affirmatively to either of the two items about physiciandiagnosed COPD or physician-diagnosed emphysema. The prevalence of physician-diagnosed chronic bronchitis was $4.4 \%(\mathrm{n}=46)$, and $5.7 \%(\mathrm{n}=60)$ responded affirmatively to the merged items of physician-diagnosed COPD, emphysema or chronic bronchitis.

Specificity, sensitivity, PPV and NPV of physiciandiagnosed COPD, physician-diagnosed COPD/emphysema and the merged item about COPD, emphysema and chronic bronchitis in relation to a different definitions of COPD and airways obstruction are shown in Table 2 .

For the single item about physician-diagnosed COPD, the sensitivity was around 0.11 and the specificity was almost 0.99 in relation to both definitions of COPD
(Table 2). The sensitivity of the combined items about COPD/emphysema in detecting COPD GOLD $_{\text {was }} 0.105$ (95\% CI 0.054-0.180), and for $\mathrm{GOLD}_{\mathrm{LLN}}$, it was $0.110(95 \%$ CI 0.056-0.188). The specificity was high, 0.985 (95\% CI 0.975-0.992), for both definitions of COPD. When the COPD items were validated in relation to airways obstruction, the sensitivity was lower, 0.057 (95\% CI $0.030-0.098$ ), but the specificity was similar, $0.985-0.989$. When the items about physician-diagnosed COPD, emphysema or chronic bronchitis were merged as one entity, the sensitivity went up (0.11-0.15) and the specificity went down (0.95) (Table 2).

When the analyses were separated according to sex (Table 3), the results were also similar, with no obvious differences according to gender. Among ever-smokers, the combined COPD/emphysema items reached a similar specificity, 0.981 (95\% CI 0.965-0.991), in relation to COPD ${ }_{\text {GOLD }}$ and $\mathrm{COPD}_{\mathrm{LLN}}$ compared to the whole population.

\section{Discussion}

The main results extracted from the present study are that items about physician-diagnosed COPD have a very high specificity (and low sensitivity) in relation to a golden standard of COPD based on spirometry after bronchodilation. Especially, the single item comprising only COPD had, in our national context, a very high specificity. Furthermore, the common approach to merge items about COPD and emphysema also has high specificity (and low sensitivity). However, combining items with COPD and chronic bronchitis resulted in lower specificity, and hence a larger degree of false positives. In this population aged 50-64 years, there

Table I Age, gender, smoking habits, symptoms and lung function values in 1,050 subjects according to different definitions of airways obstruction and COPD

\begin{tabular}{|c|c|c|c|}
\hline Variables & Airways obstruction ( $\mathbf{N}=\mathbf{2} \mid \mathbf{2})$ & $\operatorname{COPD}_{\text {GOLD }}(\mathrm{N}=105)$ & $\mathrm{COPD}_{\text {LLN }}(\mathrm{N}=100)$ \\
\hline All $(n=I, 050)$ & $20.2 \%(\mathrm{~N}=2 \mid 2)$ & $10.0 \%(\mathrm{~N}=105)$ & $9.5 \%(\mathrm{~N}=100)$ \\
\hline Males $(n=525)$ & $18.3 \%(\mathrm{~N}=96)$ & $11.4 \%(\mathrm{~N}=60)$ & $10.9 \%(\mathrm{~N}=57)$ \\
\hline Females $(n=525)$ & $22.1 \%(\mathrm{~N}=116)$ & $8.6 \%(\mathrm{~N}=45)$ & $8.2 \%(\mathrm{~N}=43)$ \\
\hline Age (years) & 58.1 & 58.7 & 58.1 \\
\hline Never-smokers $(n=448)$ & $13.2 \%(\mathrm{~N}=59)$ & $4.7 \%(\mathrm{~N}=2 \mathrm{I})$ & $7.1 \%(\mathrm{~N}=32)$ \\
\hline Ever-smokers $(\mathrm{n}=602)$ & $25.4 \%(\mathrm{~N}=153)$ & $14.0 \%(\mathrm{~N}=84)$ & $1 \mathrm{l} .3 \%(\mathrm{~N}=68)$ \\
\hline Physician-diagnosed asthma ( $\mathrm{n}=97)$ & $38.1 \%(\mathrm{~N}=37)$ & $23.7 \%(\mathrm{~N}=23)$ & $21.7 \%(\mathrm{~N}=2 \mathrm{I})$ \\
\hline $\mathrm{FEV}_{1}(\%$ pred $)$ & 90.2 & 83.1 & 86.3 \\
\hline FVC (\% pred) & 101.7 & 100.6 & 104.7 \\
\hline Current wheeze $(n=87)$ & $17.5 \%(\mathrm{~N}=37)$ & $26.7 \%(\mathrm{~N}=28)$ & $27.0 \%(\mathrm{~N}=27)$ \\
\hline Physician-diagnosed COPD/emphysema $(n=25)$ & $48.0 \%(\mathrm{~N}=12)$ & $44.0 \%(\mathrm{~N}=\mathrm{II})$ & $48.0 \%(\mathrm{~N}=12)$ \\
\hline Physician-diagnosed chronic bronchitis $(n=46)$ & $41.3 \%(\mathrm{~N}=19)$ & $19.6 \%(\mathrm{~N}=9)$ & $21.7 \%(\mathrm{~N}=10)$ \\
\hline $\begin{array}{l}\text { Physician-diagnosed COPD/emphysema or } \\
\text { chronic bronchitis }(n=60)\end{array}$ & $40.0 \%(\mathrm{~N}=24)$ & $23.3 \%(\mathrm{~N}=14)$ & $25.0 \%(\mathrm{~N}=15)$ \\
\hline
\end{tabular}

Abbreviations: $\mathrm{FEV}_{1}$, forced expiratory volume in I second; FVC, forced vital capacity; LLN lower limit of normal. 
Table 2 Validity of items about physician-diagnosed COPD and chronic bronchitis

\begin{tabular}{|c|c|c|c|c|c|c|}
\hline & \multicolumn{2}{|c|}{ Airways obstruction $(n=2 \mid 2)$} & \multicolumn{2}{|c|}{$\operatorname{COPD}_{\mathrm{GOLD}}(\mathrm{n}=105)$} & \multicolumn{2}{|c|}{$\operatorname{COPD}_{\text {LLN }}(n=100)$} \\
\hline & Value & $95 \% \mathrm{Cl}$ & Value & $95 \% \mathrm{Cl}$ & Value & $95 \% \mathrm{Cl}$ \\
\hline \multicolumn{7}{|c|}{ Physician-diagnosed COPD $(n=2 I)$} \\
\hline Sensitivity & 0.057 & $0.030-0.098$ & 0.106 & $0.054-0.181$ & 0.111 & $0.056-0.188$ \\
\hline Specificity & 0.989 & $0.980-0.995$ & 0.989 & $0.981-0.995$ & 0.989 & $0.98 I-0.995$ \\
\hline PPV & 0.571 & $0.340-0.782$ & 0.524 & $0.298-0.743$ & 0.524 & $0.299-0.743$ \\
\hline NPV & 0.806 & $0.780-0.830$ & 0.909 & $0.890-0.926$ & 0.914 & $0.895-0.930$ \\
\hline \multicolumn{7}{|c|}{ Physician-diagnosed COPD/emphysema $(n=25)$} \\
\hline Sensitivity & 0.057 & $0.030-0.097$ & 0.105 & $0.054-0.180$ & 0.110 & $0.056-0.188$ \\
\hline Specificity & 0.985 & $0.974-0.992$ & 0.985 & $0.975-0.992$ & 0.985 & $0.975-0.992$ \\
\hline PPV & 0.480 & $0.278-0.687$ & 0.440 & $0.244-0.65$ I & 0.440 & $0.244-0.65 I$ \\
\hline NPV & 0.805 & $0.779-0.829$ & 0.908 & $0.889-0.925$ & 0.913 & $0.894-0.930$ \\
\hline \multicolumn{7}{|c|}{ Physician-diagnosed chronic bronchitis $(n=46)$} \\
\hline Sensitivity & 0.090 & $0.055-0.136$ & 0.086 & $0.040-0.157$ & 0.100 & $0.049-0.176$ \\
\hline Specificity & 0.968 & $0.954-0.979$ & 0.961 & $0.946-0.972$ & 0.962 & $0.948-0.973$ \\
\hline PPV & 0.413 & $0.270-0.568$ & 0.196 & $0.094-0.339$ & 0.217 & $0.110-0.364$ \\
\hline NPV & 0.808 & $0.782-0.832$ & 0.904 & $0.885-0.922$ & 0.910 & $0.891-0.927$ \\
\hline \multicolumn{7}{|c|}{ Physician-diagnosed COPD, emphysema and chronic bronchitis $(n=60)$} \\
\hline Sensitivity & 0.113 & $0.074-0.164$ & 0.133 & $0.075-0.214$ & 0.15 & $0.087-0.235$ \\
\hline Specificity & 0.957 & $0.94 I-0.970$ & 0.951 & $0.936-0.964$ & 0.953 & $0.937-0.965$ \\
\hline PPV & 0.400 & $0.276-0.535$ & 0.233 & $0.134-0.360$ & 0.250 & $0.147-0.379$ \\
\hline NPV & 0.810 & $0.784-0.834$ & 0.908 & $0.888-0.926$ & 0.914 & $0.895-0.931$ \\
\hline
\end{tabular}

Abbreviations: NPV, negative predictive value; PPV, positive predictive value; ${ }_{\lfloor L N}$, lower limit of normal.

was no difference whether the golden standard was based on the GOLD concept or on the LLN concept. There was neither any significant difference with regard to gender.

This is, to the best of our knowledge, the first study in the general population validating questionnaire items about physician-diagnosed COPD in relation to a spirometric diagnosis of COPD. The results indicate a very high specificity, which minimizes the proportion of false positives. The PPVs are around 0.50 , with the highest values, 0.524 , for the single-item about physician-diagnosed COPD. This means that almost half of the subjects responding affirmatively to the item about physician-diagnosed COPD do not have spirometric COPD. Due to the low prevalence of physiciandiagnosed COPD, this misclassification only marginally

Table 3 Validity of items about physician-diagnosed COPD and emphysema among men, women and ever-smokers in relation with different spirometry definitions of airway obstruction and COPD

\begin{tabular}{|c|c|c|c|c|c|c|}
\hline & \multicolumn{2}{|c|}{ Airways obstruction $(n=2 \mid 2)$} & \multicolumn{2}{|c|}{$\operatorname{COPD}_{\text {GOLD }}(n=105)$} & \multicolumn{2}{|c|}{$\operatorname{COPD}_{\text {LLN }}(\mathrm{n}=100)$} \\
\hline & Value & $95 \% \mathrm{Cl}$ & Value & $95 \% \mathrm{Cl}$ & Value & $95 \% \mathrm{Cl}$ \\
\hline \multicolumn{7}{|c|}{ Physician-diagnosed COPD/emphysema $(n=25)$} \\
\hline \multicolumn{7}{|c|}{ Males $(n=14)$} \\
\hline Sensitivity & 0.063 & $0.023-0.131$ & 0.100 & $0.038-0.205$ & 0.105 & $0.040-0.215$ \\
\hline Specificity & 0.981 & $0.964-0.992$ & 0.983 & $0.967-0.993$ & 0.983 & $0.967-0.993$ \\
\hline PPV & 0.429 & $0.177-0.711$ & 0.429 & $0.177-0.711$ & 0.455 & $0.168-0.767$ \\
\hline NPV & 0.824 & $0.789-0.856$ & 0.894 & $0.864-0.920$ & 0.900 & $0.87 I-0.925$ \\
\hline \multicolumn{7}{|c|}{ Females $(n=I I)$} \\
\hline Sensitivity & 0.052 & $0.019-0.109$ & 0.111 & $0.037-0.24 I$ & 0.116 & $0.039-0.25$ I \\
\hline Specificity & 0.988 & $0.972-0.996$ & 0.988 & $0.973-0.995$ & 0.988 & $0.973-0.995$ \\
\hline PPV & 0.546 & $0.234-0.833$ & 0.455 & $0.168-0.766$ & 0.429 & $0.177-0.711$ \\
\hline NPV & 0.786 & $0.748-0.821$ & 0.922 & $0.900-0.944$ & 0.926 & $0.900-0.947$ \\
\hline \multicolumn{7}{|c|}{ Ever-smokers $(n=20)$} \\
\hline Sensitivity & 0.072 & $0.036-0.125$ & 0.119 & $0.059-0.208$ & 0.125 & $0.062-0.218$ \\
\hline Specificity & 0.980 & $0.962-0.991$ & 0.981 & $0.965-0.991$ & 0.981 & $0.965-0.991$ \\
\hline PPV & 0.550 & $0.315-0.770$ & 0.500 & $0.272-0.728$ & 0.500 & $0.272-0.728$ \\
\hline NPV & 0.756 & $0.719-0.790$ & 0.873 & $0.843-0.899$ & 0.880 & $0.851-0.905$ \\
\hline
\end{tabular}

Abbreviations: NPV, negative predictive value; PPV, positive predictive value; แN, lower limit of normal. 
affects the specificity. In the US Nurses' Health Study, the PPV for physician-diagnosed COPD, emphysema and chronic bronchitis was higher, around $0.70 .{ }^{18}$

We found in our previous study where the golden standard was spirometric airways obstruction (before bronchodilation), a sensitivity of 0.057 and specificity of 0.997 , for an item comprising both COPD and emphysema (but not chronic bronchitis). ${ }^{12}$ Those results resemble our present estimates. A very high specificity is of uttermost importance when designing epidemiological studies investigating the risk of COPD in relation to different exposures (tobacco, occupation and air pollution). When studying outcomes with low prevalence, high number of false positives will increase the misclassification, which will lead to decreased risk estimates. ${ }^{8}$

There is, however, of importance to underscore that these results and conclusions are only valid in national contexts similar to ours, that is, where there are similar traditions of diagnosing COPD. Undiagnosed COPD (false negatives) will not be detected with items about physician-diagnosed COPD. If the aim is to detect (screening) undiagnosed COPD, the most valid way is to measure lung function, which we also have performed and used as our golden standard.$^{19}$ However, in some situations spirometric investigations may be difficult to perform, and in such situations questionnaire-based identification of COPD may be an option. There are studies where many subjects can be dispersed of a large area, such as Nurses' Health Study. ${ }^{18}$ When estimating the relative risk of COPD, the false negatives is a minor problem for a correct estimation of relative risk in relation to certain exposures, as long as the misclassification is nondifferential. ${ }^{18,20}$

Items about physician-diagnosed COPD are used in epidemiological studies, but there is an obvious lack of validation and standardization of these items. One of the first groups to apply items about physician-diagnosed COPD was the Tucson Group, and they were followed by the studies from National Health and Nutrition Examination Surveys. ${ }^{21,22}$ However, the items are worded in different ways. Table 4 presents the wordings of the most common items obtained from different studies including the present study. ${ }^{12,21-25}$ The initial items comprised wordings about emphysema and chronic bronchitis, and during the last years, the term COPD have been included in some of the items. That reflects the increased acceptance of the term COPD. ${ }^{26}$

In the present study, when physician diagnosed chronic bronchitis was analyzed as one entity together with COPD and emphysema, the diagnostic accuracy decreased. This reflects that the number of false positives increased, as in current practice chronic bronchitis is not diagnosed as COPD.

Table 4 Different wordings in questionnaire items about chronic obstructive pulmonary disease

\begin{tabular}{|c|c|c|}
\hline References & Wording & Additional comments \\
\hline Lebowitz and & During the past year, have you seen a doctor for: & \\
\hline Burrows $^{21}$ & $\begin{array}{l}\text { a. Emphysema? } \\
\text { b. Chronic bronchitis? }\end{array}$ & \\
\hline Whittemore et $\mathrm{al}^{22}$ & $\begin{array}{l}\text { Has a doctor ever told you that you had chronic bronchitis? } \\
\text { Has a doctor ever told you that you had emphysema? }\end{array}$ & $\begin{array}{l}\text { Positive response to either item and } \\
\text { negative response to current asthma was } \\
\text { defined as physician-diagnosed COPD }\end{array}$ \\
\hline Schnell et $\mathrm{al}^{23}$ & $\begin{array}{l}\text { Has a doctor or other health professional ever told you that you had } \\
\text { chronic bronchitis? } \\
\text { Has a doctor or other health professional ever told you that you had } \\
\text { emphysema? }\end{array}$ & $\begin{array}{l}\text { Positive response to any was defined as } \\
\text { physician-diagnosed COPD }\end{array}$ \\
\hline Ford et $\mathrm{al}^{24}$ & $\begin{array}{l}\text { Have you ever been told by a doctor or other health professional that } \\
\text { you have COPD, emphysema or bronchitis? }\end{array}$ & $\begin{array}{l}\text { From the Behavioral Risk factor } \\
\text { Surveillance System }\end{array}$ \\
\hline Ford et $\mathrm{al}^{24}$ & $\begin{array}{l}\text { Have you been told by a doctor or other health professional that you } \\
\text { had emphysema? } \\
\text { During the past } 12 \text { months, have you been told by a doctor or other } \\
\text { health professional that you have chronic bronchitis? }\end{array}$ & $\begin{array}{l}\text { From the National Health Interview Survey } \\
\text { An affirmative response to one or both } \\
\text { questions was defined as physician- } \\
\text { diagnosed COPD }\end{array}$ \\
\hline Murgia et $\mathrm{al}^{12}$ & Have you been diagnosed by a physician as having COPD or emphysema & One item \\
\hline Mirabelli et $\mathrm{al}^{25}$ & $\begin{array}{l}\text { Have you ever been told by a doctor or other health professional that } \\
\text { you have COPD? } \\
\text { Have you been told by a doctor or other health professional that you } \\
\text { have emphysema? } \\
\text { Have you been told by a doctor or other health professional that you } \\
\text { have chronic bronchitis? }\end{array}$ & $\begin{array}{l}\text { Positive response to any of the three items } \\
\text { was defined as physician-diagnosed COPD }\end{array}$ \\
\hline Present study & $\begin{array}{l}\text { Have you ever been diagnosed by a physician as having COPD? } \\
\text { Have you been diagnosed by a physician as having emphysema? }\end{array}$ & $\begin{array}{l}\text { Positive response to any of two items was } \\
\text { defined as physician-diagnosed COPD }\end{array}$ \\
\hline Present study & Have you ever been diagnosed by a physician as having COPD? & Single item \\
\hline
\end{tabular}


Our recommendation is, hence, not to include items about chronic bronchitis in items about physician-diagnosed COPD. This is an important message, as it is quite common to include chronic bronchitis in the set of COPD items.

Previous studies have shown that women with an identical medical history are less likely to be diagnosed with COPD compared to men. ${ }^{27,28}$ However, in our study, there were marginal differences regarding specificity, sensitivity and the PPVs between men and women.

We did not exclude subjects with asthma in our analyses. In older subjects, as in our study, the items about physiciandiagnosed asthma are misclassified in relation to COPD., ${ }^{9,27}$ We could have excluded subjects with wheezing, but that would also affect subjects with COPD, why we in our main analyses kept all subjects, also those with wheezing and physician-diagnosed asthma. However, in sensitivity analyses, we excluded subjects with current wheezing and reversibility of $\mathrm{FEV}_{1}$ over $9 \%$ predicted. ${ }^{15}$ That resulted in similar results with small deviations from the main results. The sensitivity of physician-diagnosed COPD in relation to airways obstruction was 0.054 (95\% CI 0.017-0.022), in relation to $\mathrm{GOLD}_{\mathrm{GOLD}}$ was $0.106(95 \% \mathrm{CI} 0.041-0.171)$ and in relation to $\mathrm{GOLD}_{\text {LLN }}$ was 0.111 (95\% CI 0.043-0.180). The specificity was 0.990 in all three analyses.

The main weakness with the present study is the small study sample. We have outlined $95 \% \mathrm{CI}$ around our estimates to be able to judge the reliability of our results. Another limitation is the narrow age interval 50-64 years, making the conclusions only valid for that age group. Another limitation in the present study is that we have used definitions of COPD based solely on chronic airflow limitation. In the recent GOLD document, it has been proposed to define COPD as a combination of chronic airflow limitation and certain key symptoms, such as dyspnea, wheezing or cough with phlegm. ${ }^{5}$

\section{Conclusion}

In conclusion, our results indicate that questionnaire items about physician-diagnosed COPD have a very high specificity which will minimize the number of false positives, indicating that such self-reported COPD may be used in estimation of relative risks. The low sensitivity will underestimate the total burden of COPD in the general population. Items about physiciandiagnosed COPD may be used in studies of risk factors for COPD, but are not recommended in prevalence studies.

\section{Acknowledgments}

The main funding body of The Swedish CArdioPulmonary bioImage Study (SCAPIS) was the Swedish Heart and Lung
Foundation. The study was also funded by the Knut and Alice Wallenberg Foundation, the Swedish Research Council (VR), VINNOVA and the Swedish Council for Working Life, Health, and Welfare (FORTE). In addition, there was support from the Sahlgrenska University Hospital, strategic grants from ALF/LUA in Western Sweden and from the Sahlgrenska Academy at University of Gothenburg.

\section{Disclosure}

The authors report no conflicts of interest in this work.

\section{References}

1. Mannino DM, Buist AS. Global burden of COPD: risk factors, prevalence and future trends. Lancet. 2007;370(9589):765-773.

2. Balmes J, Becklake M, Blanc P, et al. ATS statement on occupational contribution to the burden of airway disease. Am J Crit Care Respir Med. 2003;167(5):787-797.

3. Lamprecht B, McBurnie MA, Vollmer WM, et al. COPD in never smokers: results from the population-based burden of obstructive lung disease study. Chest. 2011;139(4):752-763.

4. Toren K, Järvholm B. Effect of occupational exposure to vapors, gases, dusts, and fumes on COPD mortality risk among Swedish construction workers: a longitudinal cohort study. Chest. 2014;145(5):992-997.

5. Vogelmeier CF, Criner GJ, Martinez FJ, et al. Global strategy for the diagnosis, management, and prevention of chronic obstructive lung disease 2017 report. Respirology. 2017;22(3):575-601.

6. Vaz Fragoso CA, Concato J, McAvay G, et al. The ratio of FEV to $\mathrm{FVC}$ as a basis for establishing chronic obstructive pulmonary disease. Am J Respir Crit Care Med. 2010;181(5):446-451.

7. Pellegrino R, Viegi G, Brusasco V, et al. ATS/ERS Task Force: standardization of Lung function testing. Interpretative strategies for lung function tests. Eur Respir J. 2005;26:948-968.

8. Copeland KT, Checkoway H, McMichael AJ, Holbrook RH. Bias due to misclassification in the estimation of relative risk. Am J Epidemiol. 1977;105(5):488-495.

9. Torén K, Brisman J, Järvholm B. Asthma and asthma-like symptoms in adults assessed by questionnaires. Chest. 1993;104(2):600-608.

10. Torén K, Palmqvist M, Löwhagen O, Balder B, Tunsäter A. Accuracy of self-reported year of asthma-onset. J Clin Epidemiol. 2006; 59(1):90-93.

11. Oksanen T, Kivimäki M, Pentti J, Virtanen M, Klaukka T, Vahtera J. Self-report as an indicator of incident disease. Ann Epidemiol. 2010; 20(7):547-554.

12. Murgia N, Brisman J, Claesson A, Muzi G, Olin AC, Torén K. Validity of a questionnaire-based diagnosis of chronic obstructive pulmonary disease in a general population study. BMC Pulm Med. 2014;14:49.

13. Bergström G, Berglund G, Blomberg A, et al. The Swedish CArdioPulmonary BioImage Study (SCAPIS): objectives and design. J Intern Med. 2015;278(6):645-659.

14. Torén K, Olin AC, Lindberg A, et al. Vital capacity and COPD: the Swedish CArdioPulmonary BioImage Study (SCAPIS). Int J COPD. 2016;11:927-923

15. Torén K, Bake B, Olin AC, et al. Measures of bronchodilator response of $\mathrm{FEV}_{1}, \mathrm{FVC}$ and SVC in a Swedish general-population sample aged 50-64 years, the SCAPIS Pilot Study. Int J Chron Obstruct Pulmon Dis. 2017;12:973-980.

16. Brisman J, Kim JL, Olin AC, Torén K, Bake B. Spirometric reference equations in adults. Clin Physiol Funct Imaging. Epub 2016 Feb 10.

17. Brisman J, Kim JL, Olin AC, Torén K, Bake B. A physiologically based model for spirometric equations in adults. Clin Physiol Funct Imaging. 2016;36(1):77-84. 
18. Barr RG, Herbstman J, Speizer FE, Camargo CA. Validation of selfreported chronic obstructive pulmonary disease in a cohort studies of nurses. Am J Epidemiol. 2002;155(10):965-971.

19. Mannino DM. Searching for COPD: are questionnaires the right answer? COPD. 2010;7(5):313-314.

20. Brenner $\mathrm{H}$, Gefeller O. Use of the positive predictive value to correct for disease misclassification in epidemiologic studies. Am J Epidemiol. 1993;138(11):1007-1015.

21. Lebowitz MD, Burrows B. Comparison of questionnaires: the BMRC and NHLI respiratory questionnaires and a new self-completion questionnaire. Am Rev Respir Dis. 1976;113(5):627-635.

22. Whittemore AS, Perlin SA, DiCiccio Y. Chronic obstructive pulmonary disease in lifelong nonsmokers: results from NHANES. Am J Public Health. 1995;85(5):702-706.

23. Schnell K, Weiss CO, Lee T, et al. The prevalence of clinically-relevant comorbid conditions in patients with physician-diagnosed COPD: a cross-sectional study using data from NHANES 1999-2008. BMC Pulm Med. 2012;12:26.
24. Ford ES, Croft JB, Mannino DM, Wheaton AG, Zhang X, Giles WH. COPD surveillance - United States 1999-2011. Chest. 2013;144(1): 284-305.

25. Mirabelli MC, Beavers SF, Chatterjee AB. Active asthma and the prevalence of physician-diagnosed COPD. Lung. 2014;192(5):963-700.

26. Celli BR. Abnormal spirometry confirms airflow limitation but is not the only or most important characteristic of COPD. Eur Respir J. 2015; 46:1525-1526.

27. Dodge R, Cline MG, Burrows B. Comparisons of asthma, emphysema, and chronic bronchitis diagnoses in a general population sample. Am Rev Respir Dis. 1986;133(6):981-986.

28. Chapman KR, Tashkin DP, Pye DJ. Gender bias in the diagnosis of COPD. Chest. 2001;119(6):1691-1695.
International Journal of COPD

\section{Publish your work in this journal}

The International Journal of COPD is an international, peer-reviewed journal of therapeutics and pharmacology focusing on concise rapid reporting of clinical studies and reviews in COPD. Special focus is given to the pathophysiological processes underlying the disease, intervention programs, patient focused education, and self management protocols.

\section{Dovepress}

This journal is indexed on PubMed Central, MedLine and CAS. The manuscript management system is completely online and includes a very quick and fair peer-review system, which is all easy to use. Visit http://www.dovepress.com/testimonials.php to read real quotes from published authors.

Submit your manuscript here: http://www.dovepress.com/international-journal-of-chronic-obstructive-pulmonary-disease-journal 